\title{
Growth of acid fast L forms from the blood of patients with sarcoidosis
}

\author{
Peter L Almenoff, Alva Johnson, Marvin Lesser, Lida H Mattman
}

\section{Department of Medicine, \\ Veterans Affairs Medical Center Hampton, Virginia, USA \\ P L Almenoff \\ A Johnson}

Department of Medicine,

Veterans Affai:s Medical Center, Bronx, New York, USA

P L Almenoff

$M$ Lesser

Department of

Medicine,

Mount Sinai School of

Medicine, New York,

New York, USA

P L Almenoff

$M$ Lesser

Department of Microbiology,

Eastern Virginia

Medical School,

USA

A Johnson

Department of

Biology,

Wayne State

University,

Detroit, Michigan,

USA

L H Mattman

Correspondence to: Dr P L Almenoff, Division of Pulmonary/ Critical Care Medicine, Veterans Affairs Medical Center (111-G), Bronx, New York 10468, USA.

Received 11 April 1995 Returned to author 9 October 1995

Revised version received 24 November 1995 Accepted for publication 4 December 1995

\begin{abstract}
Background - Acid fast cell wall deficient forms (CWDF) of bacteria have been grown from blood, bronchial washings, and ocular anterior chamber fluid from patients with sarcoidosis. A monoclonal antibody raised against Mycobacterium tuberculosis whole cell antigen $\left(\mathrm{H}_{37} \mathrm{RV}\right)$ was used to characterise further CWDF grown from the blood of patients with sarcoidosis.

Methods - Blood from 20 patients with active sarcoidosis and from 20 controls was cultured using methods favourable for the growth of CWDF. Isolates were further characterised by indirect fluorescent antibody analysis using a monoclonal antibody highly reactive with $M$ tuberculosis.

Results - CWDF were grown from the blood of 19 of 20 subjects with sarcoidosis. All isolates stained positively with the monoclonal antibody and with a modified Kinyoun stain. No organisms were grown from the blood of controls.

Conclusions - These data demonstrate that CWDF can be grown from the blood of nearly all patients with active sarcoidosis. The results confirm that the organisms are mycobacterial in origin and are similar, if not identical, to $M$ tuberculosis. Their role in the pathogenesis of sarcoidosis is unknown.

(Thorax 1996;51:530-533)
\end{abstract}

Keywords: L form, sarcoidosis, mycobacteria.

Sarcoidosis is a multisystem disorder characterised by the presence of numerous noncaseating granulomas in many organs including lung, lymph nodes, spleen, liver, and skin. Although pathogenesis of the entity remains unclear despite intensive research efforts for nearly 90 years, cumulative findings strongly implicate mycobacteria as the causative factor. Acid fast bacilli have been detected in lymph nodes and lung tissue of patients with sarcoidosis ${ }^{1-7}$ that appear to be mycobacterial cell wall deficient forms (CWDF) ${ }^{8-11}$ Antibodies against unknown mycobacterial antigens have also been detected in the serum of most patients with sarcoidosis. ${ }^{12}$ Increased numbers of $\gamma \delta \mathrm{T}$ lymphocytes, which proliferate in response to mycobacterial antigens, are present in peripheral blood samples from patients with sarcoidosis, with expansion of the $V \delta 2$ + subset occurring in both sarcoidosis and tuberculosis. ${ }^{13-16}$ Mycobacterial nucleic acid components have been found in bronchoalveolar lavage samples, lung tissue, spleen, and lymph nodes from patients with sarcoidosis. ${ }^{17-20}$

In addition, acid fast CWDF have been grown from the blood, bronchial washings, and ocular anterior chamber fluid from patients with sarcoidosis. ${ }^{1121-24}$ Specifically, Judge ${ }^{22}$ and Mattman ${ }^{23}$ grew CWDF from 28 of 29 subjects with sarcoidosis. However, in none of these studies was it clearly shown that organisms isolated by culture were of mycobacterial origin. In this study we have therefore used a monoclonal antibody raised against $\mathrm{Myco-}$ bacterium tuberculosis $\mathrm{H}_{37} \mathrm{RV}$ whole cell antigen ${ }^{25}$ to characterise further CWDF grown from the blood of patients with sarcoidosis.

\section{Methods}

SUBJECT SELECTION

Subjects were recruited from the Veterans Administration Medical Center, Hampton, Virginia. Blood samples were obtained from subjects with clinical, radiographic, and biopsy evidence of active sarcoidosis and whose sputum was acid fast smear and culture negative for tuberculosis. ${ }^{26}$ All subjects had lung disease and, in addition, three had skin disease, one joint disease, and one central nervous system disease. Seven were receiving systemic corticosteroids. The duration of the disease ranged from 0 to 8 years. Blood samples were also obtained from healthy individuals, none of whom were known to be infected with the AIDS virus or to have a history of tuberculosis. All control individuals were skin test negative for purified protein derivative (PPD) and none had received Bacillus Calmette Guerin (BCG) vaccine. All subjects gave informed consent and the studies were approved by the Institutional Review Board.

\section{ASSESSMENT OF MONOCLONAL ANTIBODY} SPECIFICITY

A mouse monoclonal antibody was developed against $M$ tuberculosis $\mathrm{H}_{37} \mathrm{RV}$ whole cell antigen using the Kohler-Milstein technique. ${ }^{27}$ One gram of wet cell pellet of bacteria was suspended in $10 \mathrm{ml}$ of sterile distilled water and inactivated by flowing steam $\left(80-88^{\circ} \mathrm{C}\right)$ in an autoclave for one hour. The concentration of inactivated cells was adjusted to an absorbance of 0.15 in a $10 \times 75 \mathrm{~mm}$ cuvette at $450 \mathrm{~nm}$ with a Coleman Junior IIA linear absorbance spectrophometer (Model 6/20A, Perkins Elmer Coleman Instruments Division); $160 \mu \mathrm{l}$ of selected cell suspension was added to microtitre plates with Immunolon removal well strips (Dynatech Laboratories, Alexandria, Virginia, 
Reactivity of anti- $H_{37} R V$ hybridoma antibody with different species of mycobacteria and non-acid fast bacteria (ELISA) expressed as optical density

\begin{tabular}{ll}
\hline Heated antigen & Result \\
\hline $\mathrm{H}_{37} \mathrm{RV}$ & $>2 \cdot 5$ \\
$\mathrm{BCG}$ & $>2 \cdot 5$ \\
$\mathrm{H}_{37} \mathrm{RA}$ & $0 \cdot 81$ \\
M kansasii & $0 \cdot 00$ \\
M intracellulare & $0 \cdot 10$ \\
M scrofulaceum & $0 \cdot 07$ \\
M chelonae & $0 \cdot 00$ \\
M fortuitum & $0 \cdot 08$ \\
M avium & $0 \cdot 11$ \\
Pseudomonas aeruginosa & $0 \cdot 00$ \\
Escherichia coli & $0 \cdot 00$ \\
Klebsiella pneumoniae & $0 \cdot 00$ \\
Staphylococcus aureus & $0 \cdot 00$ \\
Streptococcus pyogenes & $0 \cdot 00$ \\
\hline
\end{tabular}

USA). Plates with cell suspensions were centrifuged at $1200 \mathrm{rpm}$ for 10 minutes, the wells were aspirated, washed with a Tween 80 $(0.05 \%)$ saline $(0.85 \%)$ wash solution, and filled with ethylene glycol for five minutes to fix antigen to the plastic wells. Ethylene glycol was aspirated, the wells washed, and the plates were used or stored at $4^{\circ} \mathrm{C}$ for enzyme linked immunosorbent assay (ELISA) procedures. The $\mathrm{H}_{37} \mathrm{RV}$ monoclonal antibody was added to selected antigen wells, incubated at $37^{\circ} \mathrm{C}$ for one hour, aspirated, and washed. This was followed by addition of a goat antimouse alkaline phosphatase conjugate (Sigma Chemical Co., St Louis, Missouri, USA), incubation, and a wash procedure. Finally, $160 \mu \mathrm{l}$ of alkaline phosphatase substrate (A-5153, Sigma Chemical Co.) was added to appropriate wells for incubation at room temperature for 30 minutes before recording colour development at $410 \mathrm{~nm}$ with a Dynatech ELISA minireader (Alexandria, Virginia, USA). As shown in the table, there was high absorbance with the $\mathrm{H}_{37} \mathrm{RV}, \mathrm{BCG}$, and $\mathrm{H}_{37} \mathrm{RA}$ antigens, minimal absorbance with atypical mycobacterial antigens, and no absorbance with either Gram positive or Gram negative antigens.

\section{BLOOD CULTURE ANALYSIS FOR L FORMS OF MYCOBACTERIA}

Veal infusion broth (Difco Laboratories Inc, Detroit, Michigan, USA) and glycerol (2\%, Fisher Scientific, Springfield, New Jersey, USA) were mixed and adjusted to a $\mathrm{pH}$ of $5 \cdot 5$ and combined with Noble agar $(0.09 \%$, Difco Laboratories) to make a modified veal infusion medium which was dispensed in $19 \mathrm{ml}$ aliquots in glass screw cap tubes. A $20 \%$ solution of yeast extract (No. 0127, Difco Laboratories) was prepared and dispensed in $10 \mathrm{ml}$ aliquots in separate glass screw cap tubes. The veal infusion medium and yeast extract were sterilised in an autoclave at $15 \mathrm{lbs}\left(121^{\circ}\right)$ for 15 minutes. Immediately before inoculation of the veal infusion medium with subjects' blood, $1 \mathrm{ml}$ of the fresh yeast extract $(20 \%)$ was added aseptically to $19 \mathrm{ml}$ of the veal infusion medium to prepare veal infusion medium + yeast extract $1 \%$.

Polyvinylpropylene iodine was used to clean the subject's skin and rubber stopper of a vacutainer tube containing EDTA. Approximately $2 \mathrm{ml}$ of blood (for a $10 \%$ inoculum) was drawn into a sterile Pasteur pipette and transferred to a tube containing veal infusion medium + yeast extract. The inoculum was then mixed and randomly distributed throughout the medium and incubated at $36^{\circ} \mathrm{C}$. At 48 hours $10 \mathrm{ml}$ of growth was transferred to a glass screw cap tube, $0.1 \mathrm{ml}$ of xylene was added, and the mixture was shaken by hand for five minutes. It was then allowed to stand in a vertical position for 10 minutes. The top portion of the xylene/medium emulsion was removed using a Pasteur pipette and transferred to glass slides for Gram stain, Kinyoun stain, and indirect fluorescent antibody analysis. To detect acid fast organisms, dried smears of growth from the blood cultures were fixed for three minutes using methanol. The methanol was then decanted and the smears were allowed to air dry. The primary stain, Kinyoun's carbol fuchsin, was used to flood the slides and stain the smears for five minutes. The primary stain was modified by adding $0.1 \mathrm{ml}$ of $5 \%$ sodium bicarbonate to $9.9 \mathrm{ml}$ of primary Kinyoun stain (HarleCo, Gibbston, New Jersey, USA), mixing, and filtering (no. 2 filter paper) just before use. After the primary stain was decanted the slides were flooded with $3 \% \mathrm{HCl}$ in $95 \%$ ethanol (decolouriser) and rocked on a staining rack for one minute to remove unbound stain. After decolourisation the slides were gently washed in cold water and drained. The slides were then flooded with the counterstain metanil yellow $(0.05 \%$ aqueous solution, HarleCo) for one minute, decanted, and allowed to air dry without blotting. The stained smears were placed in a slide holder at $>45^{\circ}$ for draining and drying. All washing procedures were performed with cold water from a beaker because forcibly applied water removes the loosely adherent L colonies. The smears were then examined under $20 \times$ magnification to locate acid fast microcolonies. Their typical morphology was confirmed by examination under oil immersion $(1000 \times)$.

Mycobacterial L forms were identified using the mouse monoclonal antibody raised again $M$ tuberculosis $\mathrm{H}_{37} \mathrm{RV}$ whole cell antigen. Smears were fixed as described for the Kinyoun stain. The dried fixed smear was then rehydrated by flooding the slide with $0.01 \mathrm{M}$ phosphate buffered saline (PBS), $\mathrm{pH} 7 \cdot 6$. After decanting the excess saline, the mouse anti- $\mathrm{H}_{37} \mathrm{RV}$ monoclonal antibody diluted in $0.01 \mathrm{M}$ PBS, $\mathrm{pH} 7 \cdot 6$, was added to the smears which were incubated in a moist chamber at $37^{\circ} \mathrm{C}$ for 30 minutes. After incubation the monoclonal antibody was decanted and the smears were gently washed in cold PBS, $\mathrm{pH} 7 \cdot 6$, to remove unbound monoclonal antibody. The washing process was followed by the addition of goat antimouse IgG fluorescein isothiocyanate (FITC) conjugate (Sigma) to the smears for 20 minutes in a dark moist chamber at $37^{\circ} \mathrm{C}$. After incubation, unbound conjugate was washed from the smears and glycerol/PBS mounting fluid $(10 \mathrm{ml}$ glycerol $+1 \mathrm{ml}$ of PBS, pH 9.0) was added. After applying a glass cover slip the slides were examined with a Leitz Laborlux D fluorescence microscrope (Ernst Leitz Wetzlar GmbH, West Germany) 


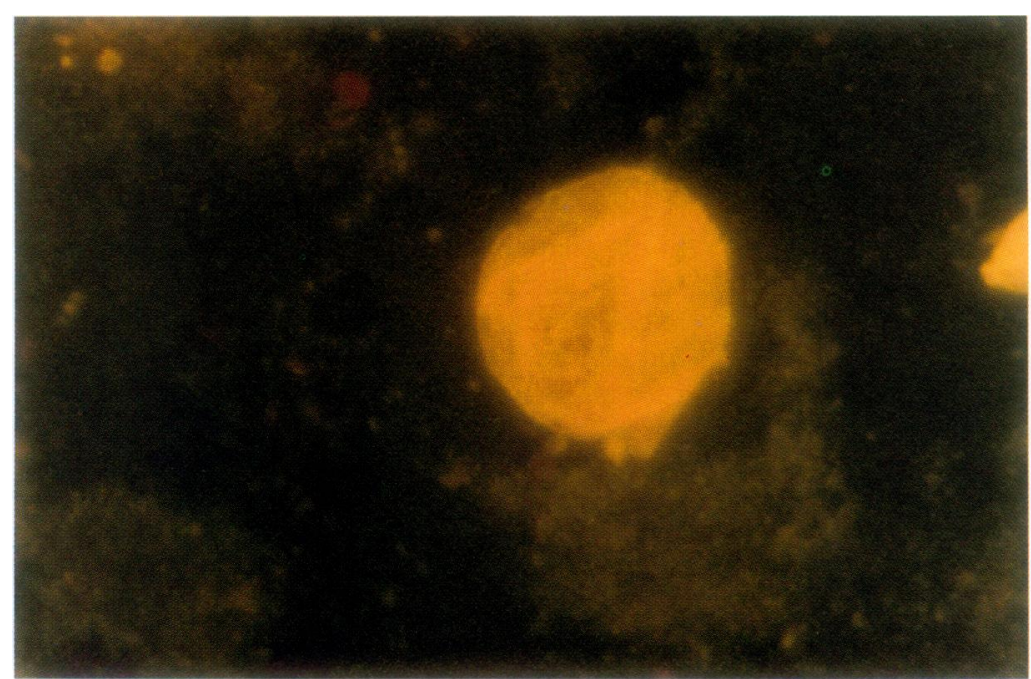

Figure 1 Photomicrograph showing cell wall deficient forms (CWDF) grown from the blood of a patient with active sarcoidosis using the Mycobacterium tuberculosis $H_{37} R V$ monocloncal antibody. A large yellow fluorescing $L$ body is seen in the centre, and small yellow fluorescing microcolonies $(\times 400)$ are seen elsewhere.

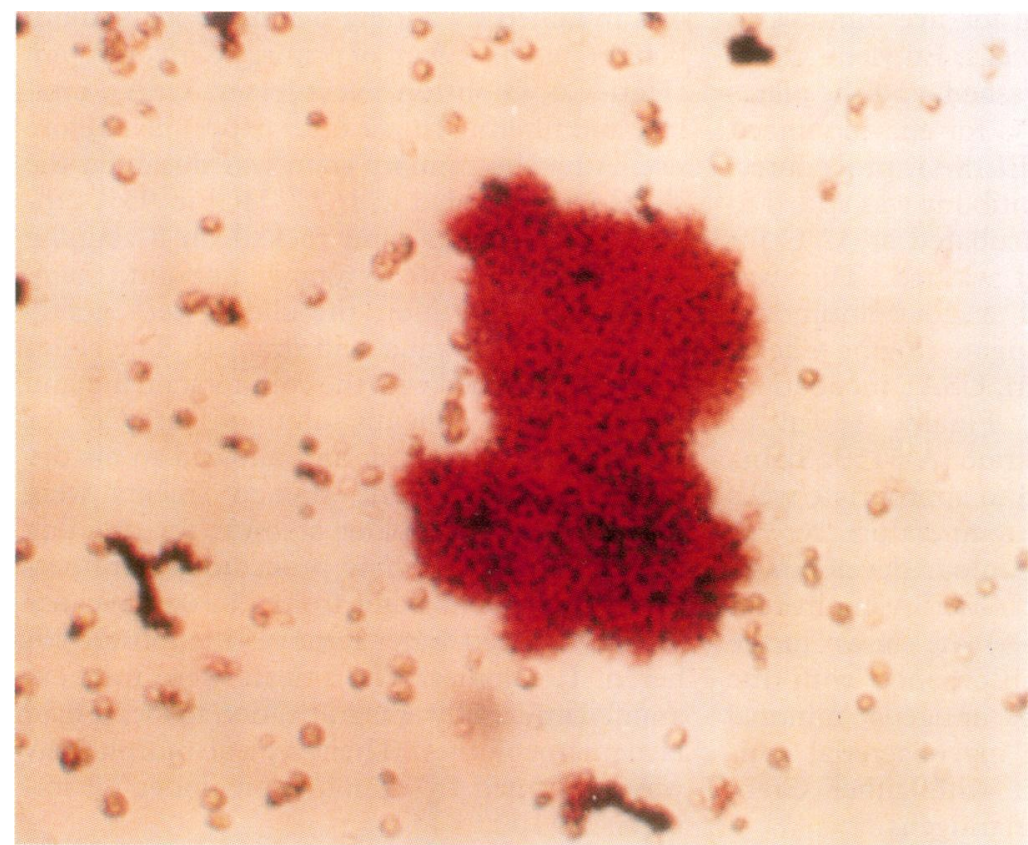

Figure 2 Photomicrograph showing cell wall deficient forms (CWDF) grown from the blood of a patient with active sarcoidosis. Using a modified Kinyoun stain, acid fast microcolonies are seen in the centre and red cells are seen in the background $(\times 200)$. The microcolonies are granular in appearance and red in colour (acid fast).

\section{Results}

A total of 40 subjects were studied. One group consisted of 20 subjects with documented sarcoidosis, and the second group consisted of 20 controls. During the study the two investigators (AJ and LHM) who performed the indirect fluorescent antibody analysis and modified Kinyoun stains were blinded to the final diagnosis. Subsequent decoding revealed that cell wall deficient bacteria grew from the blood of 19 of 20 subjects $(95 \%)$ with sarcoidosis. All organisms were reactive with the $\mathrm{H}_{37} \mathrm{RV}$ monoclonal antibody, with obvious fluorescing microcolonies and L bodies (fig 1). All smears also stained positively with the modified Kinyoun stain (fig 2). No CWDF were detected in the blood of healthy controls by either indirect fluorescent antibody analysis or modified Kinyoun stain.

\section{Discussion}

Acid fast organisms were grown successfully from the blood of 19 of 20 patients with active sarcoidosis, whereas no organisms were grown from the blood of 20 controls. Findings of variable size, predominantly coccoid forms, larger L forms, and short acid fast rods suggested that the organisms were CWDF of mycobacteria. It has previously been established that these organisms grow a few millimetres below the surface in semisolid broth under microaerophilic conditions, but are unable to multiply under strictly anaerobic conditions. ${ }^{23}$ The organisms do not depend on hypertonicity, as is true for many CWDF, and growth within red cells is a common characteristic. However, unlike CWDF grown from the blood of patients with tuberculosis, which revert to their wild type in vivo (intact cell wall) in the presence of antibiotics, the organisms grown from the blood of patients with sarcoidosis do not revert to a wild type under any culture condition. Our findings confirm previous observations that a CWDF can be grown from the blood of nearly all patients with sarcoidosis. ${ }^{2122}$

The acid fast organisms grown from the blood of patients with sarcoidosis also stained positively with the $\mathrm{H}_{37} \mathrm{RV}$ monoclonal antibody which was raised against $M$ tuberculosis $\mathrm{H}_{37} \mathrm{RV}$ whole cell antigen. ${ }^{25}$ The antibody is weakly reactive to mycobacteria other than $M$ tuberculosis and does not react with Gram negative or Gram positive bacteria. Our findings therefore confirm that CWDF isolated from patients with sarcoidosis belong to the mycobacterial family.

The fact that most patients with sarcoidosis were chronically colonised with a mycobacterial organism does not necessarily imply that the organism is the cause of the disease. However, in a detailed animal study Judge ${ }^{22}$ observed that granulomatous lesions developed in many organs including the lung, liver, spleen, kidney, and eye in mice, gerbils, and guinea pigs following intraperitoneal instillation of CWDF grown from the blood of patients with sarcoidosis. Histological changes occurred as early as 19 days after injection and were more widespread in animals simultaneously given cortisone. Organisms identical to those injected were recovered by culture from the blood and body tissues of the animals. Similarly, Barth et $a l^{11}$ induced "non-consolidated nodularity" in the lungs of mice inoculated with cortisone and acid fast CWDF grown from anterior chamber fluid from the eye of a patient with sarcoidosis. In an extensive series of studies by Mitchell et $a l^{28}$ it was shown that, although mycobacterial organisms were not specifically identified, homogenates of human sarcoidosis tissue injected into the foot pads of mice caused the slow development of widely disseminated granulomas in lymph nodes, lung, liver, spleen, and muscle, that were associated with the development of a positive Kveim reaction. Granulomatous changes were transmitted through four consecutive animal passages.

In contrast, other investigators have failed to find evidence implicating mycobacteria as causative factors in sarcoidosis. Specifically, in several studies using fluorescence and electron 
microscopy or varied culture methods, no evidence of mycobacteria or mycobacterial fragments was found in granulomatous tissue from patients with sarcoidosis. ${ }^{2930}$ In addition, although Taub et al $^{31}$ were able to induce granulomas in the foot pads of mice with homogenates of lymph nodes from patients with sarcoidosis, the changes were restricted to the site of injection and no abnormalities developed in lymph nodes, liver, spleen, or lung, and there was no response to Kveim antigen. However, since the samples were homogenised prior to injection, the growth of organisms may have been altered. Interestingly, no granulomas developed following freezing and thawing of homogenates. It has previously been reported that CWDF (spheroblasts) of $M$ tuberculosis caused no pathological changes when instilled intratracheally into guinea pigs, even though the organisms persisted in the lungs for prolonged periods of time. ${ }^{32}$

In general, recent molecular biology studies have found a link between mycobacteria and sarcoidosis. Saboor et al ${ }^{17}$ found $M$ tuberculosis DNA in $50 \%$ of patients with sarcoidosis and non-tuberculosis mycobacterial DNA in a further $20 \%$, using a complex specific insertion sequence IS986/IS6110 to detect DNA from $M$ tuberculosis complex bacteria and the conserved sequences of the mycobacterial groEL gene to detect DNA from mycobacteria other than $M$ tuberculosis. The false positive polymerase chain reaction (PCR) rate for $M$ tuberculosis was $9 \%$. In a similar study using the same primers the authors found $M$ tuberculosis DNA in granulomatous tissue from seven of 16 patients with sarcoidosis. ${ }^{18}$ Mitchell et al ${ }^{19}$ used liquid phase DNA/RNA hybridisation with a DNA probe specific for the rRNA of the $M$ tuberculosis complex and found that hybridisation with spleen tissue from patients with sarcoidosis was $4 \cdot 8$ times higher than that with normal spleens. By contrast, Bocart $e t a^{33}$ found $M$ tuberculosis DNA in tissue samples from only two of 18 patients with sarcoidosis using several oligonucleotide primers including the IS6110 insertion element. However, no patients with proven tuberculosis were included as positive controls. With the use of paraffin embedded tissue samples and PCR amplification, Popper et al found strong signals for mycobacterial DNA in two of 15 samples from patients with sarcoidosis, ${ }^{20}$ whereas Ghossein et al ${ }^{34}$ failed to find mycobacterial DNA in samples from 10 patients using similar techniques.

In this study we have shown that organisms grown from the blood of patients with sarcoidosis are mycobacterial in origin. It is anticipated that specific DNA sequencing will be necessary to determine whether these organisms are CWDF of $M$ tuberculosis, a closely related atypical organism, or a unique species.

1 Vanek J. Acid-fast bacilli of mycobacterial nature in sarcoidosis. Beitr Path Anat 1968;136:303-15.

2 Koch ML, Cote RA. Comparison of fluorescence microscopy with Ziehl-Neelsen stain for demonstration of acidfast bacilli in smear preparations and tissue sections. $A m$ Rev Respir Dis 1965;91:283-4.

3 Vanek J, Schwarz J. Demonstration of acid-fast rods in sarcoidosis. Am Rev Respir Dis 1970;101:395-400.

4 Greenberg SD, Gyorkey F, Weg JG, Jenkins DE, Gyorkey
P. The ultrastructure of the pulmonary granuloma in "sarcoidosis". Am Rev Respir Dis 1970;102:648-52.

5 Schaumann J. On the nature of certain peculiar corpuscles present in tissue of lymphogranulomatosis benigna. Acta Med Scand 1941;106:239-53.

6 Vira B, Rosenberg MZ, Meyer J. Spindle-shaped, yeastlike, acid-fast structures in lymph nodes. Am $\mathcal{F}$ Clin Pathol 1968;49:254-5.

7 Baro C, Butt CG. Hamazaki-Wesenberg bodies in sarcoidosis. Lab Med Bull Pathol 1969;10:281.

8 Moscovic EA. Sarcoidosis and mycobacterial L-forms. Pathol Ann 1978;13:69-164.

9 Cantwell AR. Histologic observations of variably acid-fast pleomorphic bacteria in systemic sarcoidosis: a report of three cases. Growth 1982;46:113-25.

10 Cantwell AR. Variably acid-fast bacteria in a case of systemic sarcoidosis and hypodermitis sclerodermiformis. Dermatologica 1981;163:239-48.

11 Barth CL, Judge MS, Mattman LH, Hessburg PC. Isolation of an acid-fast organism from the aqueous humor in a case of sarcoidosis. Henry Ford Hosp Med f 1979;27: 127-33.

12 Chapman JS. Mycobacterial and mycotic antibodies in sera of patients with sarcoidosis. Ann Intern Med 1961;55: of patients

13 Janis EM, Kaufmann SHE, Schwartz RH, Pardoll DM, Activation of $\gamma \delta \mathrm{T}$ cells in the primary immune response Activation of $\gamma \delta$ T cells in the primary immune response

14 Kabelitz D, Bender A, Schondelmaier S, Schoel B, Kaufmann SHE. A large fraction of human peripheral blood $\gamma / \delta+T$ cells is activated by Mycobacterium tuberculosis but not by its $65-\mathrm{kD}$ heat shock protein. $\mathcal{F}$ Exp Med 1990; 171:667-79.

15 Balbi B, Moller DR, Kirby M, Holroyd KJ, Crystal RG. Increased numbers of $T$ lymphocytes with $\gamma \delta$-positive antigen receptors in a subgroup of individuals with pulmonary sarcoidosis. 7 Clin Invest 1990;85:1353-61.

16 Balbi B, Valle MT, Oddera S, Giunti D, Manca F, Rossi GA, et al. T-lymphocytes with $\gamma \delta+\mathrm{V} \delta 2+$ antigen receptors are present in increased proportions in a fraction of patients with tuberculosis or with sarcoidosis. Am Rev Respir Dis with tuberculosis or

17 Saboor SA, McI Johnson N, McFadden J. Detection of mycobacterial DNA in sarcoidosis and tuberculosis with polymerase chain reaction. Lancet 1992;339:1012-5.

18 Fidler HM, Rook GA, McI Johnson N, McFadden J. Mycobacterium tuberculosis DNA in tissue affected by sarcoidosis. BMF 1993;306:546-9.

19 Mitchell IC, Turk JL, Mitchell DN. Detection of mycobacterial rRNA in sarcoidosis with liquid-phase hybridisation. Lancet 1992;339:1015-7.

20 Popper HH, Winter E, Hofler G. DNA of Mycobacterium tuberculosis in formalin-fixed, paraffin-embedded tissue in tuberculosis and sarcoidosis detected by polymerase chain reaction. Am f Clin Pathol 1994;101:738-41.

21 Judge MS, Mattman LH. Cell wall deficient Mycobacteria in tuberculosis, sarcoidosis, and leprosy. In: Domingue in tuberculosis, sarcoidosis, and leprosy. In: Domingue GJ, ed. Cell wall deficient bacteria.

22 Judge MS. Evidence implicating a mycobacterium as the causative agent of sarcoidosis, and comparison of this organism with the blood-borne mycobacterium of tuberculosis. PhD Dissertation, Wayne State University, Detroit, 1979.

23 Mattman LH. Cell wall deficient forms. 2nd edn. Boca Raton: CRC Press, 1993:187-95.

24 Khomenko AG, Golyshevskaya VI, Elshanskaya MP. Bacteriological study of bronchoalveolar washings and blood plasma in sarcoidosis patients. Klin Med (Moscow) 1987; 65:80-4.

25 Johnson AH, Wright GL, Chaparas SD, Mancuso DJ. Analytical gradient polyacrylamide gel-crossed line immunoelectrophoresis. A technique for locating species specific Mycobacterium tuberculosis $\mathrm{H}_{37} \mathrm{RV}$ antigens in polyacrylamide gel columns. Immunol Commun 1980;9:595-609.

26 American Thoracic Society. Diagnostic standards and classification of tuberculosis. Am Rev Respir Dis 1990;142: 725-35.

27 Kohler G, Milstein C. Continuous cultures of fused cells secreting antibody of predefined specificity. Nature 1975 256:495-7.

28 Mitchell DN, Rees RJW, Goswami KKA. Transmissible agents from human sarcoid and Crohn's disease tissues. Lancet 1976;ii:761-5.

29 Bowman BU, Koehler RM, Kubina G. On the isolation of infectious agents from granulomas of patients with sarcoid. infectious agents from granulomas of

30 Wilner G, Nassar SA, Siket A, Azar HA. Fluorescent staining for mycobacteria in sarcoid and tuberculous granulomas. Am f Clin Pathol 1969;51:584-90.

31 Taub RN, Sachar D, Siltzbach LE, Janowitz H. Transmission of ileitis and sarcoid granulomas to mice. Trans Assoc Am Phys 1974;87:219-24.

32 Ratnam S, Chandrasekhar S. The pathogenicity of spheroplasts of Mycobacterium tuberculosis. Am Rev Respir Dis 1976;114:549-54.

33 Bocart D, Lecossier D, De Lassence A, Valeyre D, Battest $\mathrm{J}-\mathrm{P}$, Hance AJ. A search for mycobacterial DNA in granulomatous tissues from patients with sarcoidosis using the polymerase chain reaction. Am Rev Respir Dis 1992;145. 1142-8.

34 Ghossein RA, Ross DG, Salomon RN, Rabson AR. A search for mycobacterial DNA in sarcoidosis using the polymerase chain reaction. Am f Clin Pathol 1994;101:733-7. 